\title{
Emergence and Evolution of Social Constructionist Ideas: A Conversation with Sheila McNamee*
}

\author{
Emergencia y evolución de las ideas de construccionismo \\ social: una conversación con Sheila McNamee
}

Recibido: mayo 19 de 2013 | Revisado: junio 11 de 2013 | Aceptado: junio 11 de 2013

\author{
Nelvia Victoria Lugo ** \\ Universidad de Caldas, Colombia \\ RiCARDO ANDRÉS CELIS *** \\ Universidad de Manizales, Colombia \\ SHEILA MCNAMEE ***** \\ New Hampshire University, United States
}

doi:10.11144/Javeriana.UPSY13-1.eesc

Para citar esta entrevista: Lugo, N. V., Celis, R. A., $\&$ McNamee, S. (2014). Emergence and evolution of social constructionist ideas: A conversation with Sheila McNamee. Universitas Psychologica, 13(1), 381-390. doi:10.11144/Javeriana.UPSY13-1.eesc

* Interview made by N. Victoria Lugo and Ricardo Celis at the Universidad de Manizales. Sheila McNamee visited Manizales (Colombia) supported by Fulbright Foundation and Universidad de Caldas, on June 2012.

* Professor at Universidad de Caldas in Colombia. E-mail: victoria.lugo@ucaldas.edu.co

*** Professor at Universidad de Manizales in Colombia. Coordinator of Systemic Psychotherapy and Consulting specialization at Universidad de Manizales.E-mail: ricardocelis@umanizales.edu.co

****** Professor, University of New Hampshire, Founder and Vice President, The Taos Institute (taosinstitute.net).

\section{A B S T R A C T}

The interview first addresses the relationship between social construction, communication and systems theory, amplifying their commonalities and disagreements. Then, we trace the influence of postmodernism and the Chicago School in the rise of social construction, two of the many influences for social construction. Finally, we talk about two key concepts for social construction: generative dialogue and relational responsibility. We explore the future of social construction and its evolution to relational construction. Key words authors Social construction, systems theory, generative dialogue, relational responsibility.

\section{RES UMEN}

La entrevista se dirige primero a la relación entre la construcción social, comunicación y la teoría de sistemas, amplificando sus comunalidades y desacuerdos. Luego, se traza la influencia del postmodernismo y la Escuela de Chicago en el surgimiento de la construcción social, dos de las muchas influencias para la construcción social. Finalmente, nosotros hablamos acerca de dos conceptos claves para la construcción social: diálogo generativo y responsabilidad relacional. Exploramos el futuro del construccionismo social y su evolución a la construcción relacional.

Palabras clave autores

Construccionismo social, teoría de sistemas, diálogo generativo, responsabilidad relacional. 


\section{A brief biography of Sheila McNamee}

Sheila McNamee, Ph.D., is a Professor of Communication at the University of New Hampshire, USA. She is co-founder and Vice President the Taos Institute (taosinstitute.net). She is Affiliate Faculty at Tilburg University (The Netherlands) and is the 2001 recipient of the Class of 1944 Professorship and the 2007/2008 recipient of the Lindberg Award for outstanding Scholar/Teacher (both at the University of New Hampshire). Her work is focused on dialogic transformation within a variety of social and institutional contexts including psychotherapy, organizations, education, health care, and communities. She is the author of Relational Responsibility: Resources for Sustainable Dialogue, with Kenneth Gergen (Sage, 1999). Other books include, Therapy as Social Construction, with Kenneth Gergen (Sage, 1992), Philosophy in Therapy: The Social Poetics of Therapeutic Conversation, with Klaus Deissler (Carl Auer Systeme Verlag, 2000), The Appreciative Organization, with her co-founders of the Taos Institute (Taos Institute, 2001), The Social Construction of Organization with Dian Marie Hosking (Liber and Copenhagen Business School Press, 2006), and Research and Social Change: A Relational Constructionist Approach with Dian Marie Hosking (Routledge, 2012).

Professor McNamee has also authored numerous articles and chapters on social constructionist theory and practice. She actively engages constructionist practices in a variety of contexts to bring communities of participants with diametrically opposing viewpoints together to create livable futures. Professor McNamee lectures and consults regularly, both nationally and internationally, for universities, private institutes, organizations, and communities.

\section{Communication, systems theory and social construction}

RAC: The first question that creates a lot of curiosity to us is: what is the bridge between communication and psychotherapy? How do those worlds get together? How does a communication specialist arrive into psychotherapy?

Sheila McNamee. For me, the connection between the study of communication and psychotherapy is an intimate and important connection. Traditional psychotherapy has presumed that we need to study the psyche in order to change a person's behavior or way of being in the world. From my point of view, what we really want to change is the way in which people communicate and relate with one another. And so, I take the orientation that we create our understanding about our worlds and ourselves in our interactions. At the time that I was a graduate student studying communication, the field of family therapy, based on communication theory, was gaining strength.

The work of the Palo Alto group, in California was,initiated mostly by Gregory Bateson, and later elaborated by many people, who worked with Gregory Bateson's ideas, as I did, in understanding family dynamics instead of looking at the person as the problem. The idea was to look at the ways in which families communicate and create patterns of interaction. The earliest elaboration of this focus on interaction was from a systems point of view. So, that was the point at which communication theory and psychotherapy started to merge and become one. From there we have had a long evolution, starting with systems theory and then moving to systemic work, and then the evolving into constructionist ideas.

NVL. I believe that Ricardo's question also has to do with our educational system here in Colombia, where therapists almost always - I would say always- are psychologists. For us, therapy is closer to psychology than to communication, so it is very rare to see a communication specialist becoming a therapist.

Sheila McNamee. In the United States that is as well the practice. I completed a special training in order to be able to practice as a therapist. Training simply in communication as a discipline is not sufficient for a practicing psychotherapist. However, I do think that coming from a background of understanding the complexity of human communication really helps to understand what is 
happening in the dynamics of someone's life and, therefore, becomes a useful way of entering into the therapeutic process. I would not even use the term "psychotherapy" because I'm not particularly interested in psychological processes: I am interested in interactive processes.

RAC. We could locate the beginning of family therapy in the 1950s, which emerged very strongly with some authors as Salvador Minuchin, Haley, and Palo Alto school. Years passed and there were new developments. We started talking about constructivism, radical constructivism, and now it comes to social construction. My question is, what does social construction take from these classic authors and what is not adopted? Is there a relationship between the principles of systems theory and social construction?

Sheila McNamee. There are probably a lot of different ways to address the connections of all of these different strands of work. I will tell you how I understand it and this has a lot to do with my own evolution through the ideas. I think there could be other ways of describing these connections, but this is the way I understand them. I understand that there are two different disciplines, essentially, developing in two different ways: We have in Sociology and in Social Psychology people beginning to play with the ideas of social construction. In Sociology, in particular, people were influenced by the work of Berger and Luckman's classic text, The social construction of reality. At the same time, we have in the family therapy field an evolution of ideas emanating from Bateson's work and the idea of systems theory. So first, we have a movement away from an individual orientation, where we focus on the individual and his or her traits, actions, etc., to now understanding systems, and family systems in particular.

This shift to a focus on systems entails using the ideas from systems theory of feedback, structure, hierarchy and homeostasis as we examine how family patterns create pathologies or problems. The shift is from identifying the person as the problem to understanding the interactive pattern as the problem. This was a really innovative and important move in the evolution of how we think about psychotherapy.
Minuchin, for example, picks up certain concepts from systems theory. In particular, he focused on the concepts of hierarchy, structure, and boundaries within systems. We have Haley and the Mental Research Institute, known as strategic therapy, who pick up different concepts from systems theory, such as positive and negative feedback, family homeostasis, rules, and so on. They all were working with systems theory, but they were just highlighting and playing with different concepts from systems theory. Those ideas were very generative, mainly because these systems approaches, although different from each other, shared the assumption that we were no longer treating the individual as an object of study. Problems were not viewed as residing within the individual. It was, instead, the family's pattern of interaction that was the problem.

Next, the idea of second-order cybernetics emerged, where the therapist recognized his or her part in creating the system. In other words, there was an acknowledgment that the questions a therapists asks creates possibilities or constraints in how the family talks about itself and how we understand the family. This was a move from systems theory or what is known as first-order cybernetics to second-order cybernetics (otherwise known as the study of "observing systems"). Those interested in the idea of "observing systems" found an affinity with radical constructivists. The emphasis was on the recognition that we are part of constructing the world that we live in and by looking at the ways in which a therapist, in particular, interacts with a family; we acknowledge that the therapist is part of constructing the family. Ernst von Glasersfeld was very popular in radical constructivism.

The Milan Systemic orientation was very involved in the views of second order cybernetics. The Milan group was doing something really interesting in the sense that they were completely focused on the part that the therapist plays. They became interested in how people construct their worlds in what they do together. To that end, the interactions of therapist and family could be seen as constructing certain possibilities as well as certain constraints. Karl Tomm in Canada introduced the Milan associates, Gianfranco Cecchin and Luigi Boscolo in 
particular, to the communication theorists whom I was working with at the time, thereby explicitly introducing a communication theory that was rooted in the social construction. This theory, developed by Barnett Pearce and Vernon Cronen, was called the "Coordinated Management of Meaning theory." Karl Tomm, Gianfranco Cecchin, and Luigi Boscolo became very interested in this communication theory as a way of understanding how people construct reality in the way they talk, act and relate with one another. This was, at the time, very coherent with the evolution from systems theory, since systems theory also focused on communication. Yet, it was also very different in that moment. In fact, my $\mathrm{PhD}$ dissertation was about the Milan school of therapy and this particular communication theory.

In the marriage, if you will, between Milan Systemic Therapy and the Coordinated Management Meaning Theory we had a clearly articulated focus on communication patterns, and less of an influence from systems theory. The focus was more on how people are creating meaning together; how people create reality. That is where, I think, social construction explicitly entered into the world of psychotherapy. In many ways, it replaced the language of systems theory as a way to understand psychopathology and family dynamics with the language of communication or language as the focus of attention. The language of social construction started to take hold at that time, in the nineties.

NVL. Do you think that social construction is like another step, another moment of systemic therapy evolution or is it a completely different movement?

Sheila McNamee. I think it is a variation on a theme. I think the language of systems theory and second order cybernetics was incredibly generative and useful when we look back at the evolution. We can see the movement away from the focus on individual and individual pathology residing within the person. I think that, over time, the language of systems became limited in some way because we were still looking at people (individuals) interacting. I think when we move to social construction, we are looking at the interaction, itself; it is about the process. So in a very subtle way, while I think second-order cybernetics and the systems work successfully shifted our attention to patterns, they were still looking at people who are producing these patterns. Thus, individuals were still the primary focus. When we step into a constructionist philosophical stance, we are looking at the process, completely.

RAC. What I see is that some constructionists take into account systems theory. I have a prejudice. I am not sure if it is valid or not. When a constructionist reads systems theory, I think s/he reads open systems theory (Bertalanfy), but s/he does not read autopoietic-closed systems theory, more like Maturana. The focus of closed systems theory is the interaction, what happens with the elements and interacting parts. Yet, a focus on open systems explores how the interaction constructs the relationship. Then, is social construction closer to the idea of open systems theory and not Maturana's autopoietic-closed system?

Sheila McNamee. First, I would say I do not think social construction has taken anything from systems theory, frankly. It is as if two people are traveling on parallel roads, using different ways of talking about very similar processes, trying to articulate processes but using different languages. That is how I see social construction and systems. I think the people who have been using systems theory in psychotherapy saw the utility of the language of social construction and brought that into the work they were already doing from a systems perspective. But most social constructionists do not know about (or refer to) systems theory -von Bertalanfy- open systems, nor Maturana and autopoietic systems. In fact, many social constructionists would not even reference Gregory Bateson as a significant source. So they are two different disciplines in that regard. They draw on different literatures. Here is a way to understanding the difference: the discipline of social construction emerges within an academic discipline, mostly social psychology, communication, and sociology. Systems theory emerged within more a practitioner-oriented discipline of family therapy. So I think we just have two different discourses. The reason the three of us are sitting here talking about all of this is due to the work of some pioneering people like Karl Tomm. He and Lynn 
Hoffman were central in making connections between these two discourses.

I would add that I feel privileged in my position because, in the academic discipline of communication, as well as Social Psychology and Sociology, constructionist ideas were already circulating. I had an interest in taking those ideas and putting them into practice, and I was very interested in the therapeutic process. From my PhD work until now, putting theory to practice has been very important for me. I am not just interested in the academic examination of communication patterns. I wanted to look at them in the domain of therapy, organizational change and community change. I think it is those kinds of hybrid movements that I've been lucky enough to be a part of; there are many of us who do this kind of work, and we have attempted to bring these two worlds together in a way that probably would not have happened if we had not tried to put constructionist ideas into practice.

NVL. Why do you think these two disciplines -social construction and systems theory- are connected in Colombia?

Sheila McNamee. I have a theory. I do not know if it is correct. Some therapists in Colombia have been influenced and supported by Peter Lang from Kensington Consultation Center in London. Peter Lang was with others and me in Calgary, Canada, at the time that Karl Tomm brought us, as communication theorists and the Milan systemic ideas, (Cecchin and Boscolo) together. So we had social construction meeting systemic practice. Peter Lang developed what he came to call "Systemic Constructionist Practice" and some therapists in Colombia adopted Peter Lang's model. From there, many systemically constructionist oriented programs emerged in different universities around Colombia, offering systemic training from a constructionist point of view.

RAC. I have an idea about this story: perhaps the school with the larger tradition in systemic training, in Colombia, is Santo Tomás University. Systemic therapy training departed from the structural and strategic models, which was typically taught within most of the systems therapy training programs. Subsequently, after some years, they faced constructivism, which gave a lot of strength to radical constructivism, obviously rooted in systems theory. More recently, in the last two decades, training programs started teaching the work of authors such as Gergen, McNamee, Schnitman, all constructionists, and the conversation shifted. This development has centered social construction hand in hand with systems theory. They have not separated them. In Colombia, that is my version. It has created a very strong synergy between social construction and systems theory.

Sheila McNamee. That is exactly what I mean. In the Colombian context and also to some extent in the British context, for many people, these two are connected, social construction and systemic work, but not for everyone.

NVL. Is it the same in Latin America as in Colombia?

Sheila McNamee. I think so. I think largely yes. Although, I think in Brazil, where I've done a lot of work, there are several people whose grounding is in social construction. They never really did have systemic training, especially those who are younger people, learning in the last 10, 15 or maybe 20 years. The older generation is very much grounded in this systemic-constructionist unity, but the younger generation may not know about the systemic work.

\section{Social construction, Postmodernism and Chicago School}

RAC. Maybe we could think social construction was born more from the postmodernist philosophers like Derrida, Guattari and Deleuze, all philosophers. But there are other scholars who entered via therapy and systemic therapy in particular. What I see is that there is an interesting academic tension, and it has implications that could be relevant in the action.

Sheila McNamee. I agree, social construction is a philosophical orientation, and I would say it is one of the many elaborations of postmodern ideas.

NVL. When Sheila says that social construction is a philosophical orientation, it suggests to me that it is a way of being, rather than a theory or a technique. It is as a posture, an attitude or 
a tone in the relationship or conversation with others. This involves a way of thinking, speaking and acting. That is when a philosophical orientation becomes a philosophy of life, a way of seeing the world, knowledge, language, and relationship. Social construction takes from postmodernism some interesting ideas, like questioning the idea of universal knowledge and privileging, instead, local knowledge, relevant to the community. It also questions the centrality of individual and objective knowledge about the world. All of the ideas of modernism (universal knowledge, objectivity, etc.) have been taken for granted but can be reflected upon and critiqued. I find it very interesting to understand knowledge, as a social process that emerges between people, in what they do together and therefore, is inherently transformative.

Sheila McNamee. Yes. This is particularly important to me. To talk about social construction as a philosophical stance is to embrace the idea of a way of orienting ourselves to each other and the world. Yet, it is not a Truth, nor a "better" way to be in the world. Social construction acknowledges all theories, all discourses, as potential resources for action. Thus, our focus is not on "discovering" the "right" way to do things but the generative, useful way to go on together in the world. The way we know and understand the world is the byproduct of our interactions with each other. And, we must remember, that our interactions always take place in historical, cultural, and local contexts. The traditions within which we operate and the local, situated engagements in which we are involved generate us a sense of what is right and good, wrong and bad. These "truths" are always local, fluid, and open to transformation.

NVL. Sheila, I wanted to ask you about the influence that sociologists of the Chicago School have had on social construction. How does social construction integrate (or not) these ideas from sociologists in the United States?

Sheila McNamee. The Chicago School, like many other schools of thought, has been a very important part of social construction and the development of social constructionist theory. The way that many of us see it is that, in particularly, the Chicago School was really attempting to move toward an understanding of the relational - of the social - as the center of creating understanding and meaning and, most particularly, creating a sense of self and identity. So, social construction owes a lot to the work of the Chicago School and at the same time, there is a sense, if you look back at that work, that while there is an emphasis on the social, the starting place is still the individual. Basically, the question confronted by the Chicago School is, how do I understand myself through my relationship with you? So we are still trying to understand how a person understands.

A constructionist perspective today - and I have to say it was not always so, Berger and Luckman are still in that Chicago School frame - has moved further along in not privileging always the individual as the starting place. Instead, we focus on what many of us refer to as the "in between," the process of what people are doing. We view meaning, knowledge as emerging within relational processes. So our focus is not on individuals but on the process: what people are doing together. What are their actions, their co-actions making? What possibilities and constraints are emerging from that making? The work of the Chicago School has been informative and formative of constructionist ideas, and over time we have pushed further into what I would call the relational, the radically relational.

NVL. Yes, I think it is also important to recognize that these sociologists such as Garfinkel and Goffman were really interested in social interaction; they tried to see the individual as a social actor on a stage that is part of relationships in a micro-world. This sociology was more interested in the micro than in the macro, highlighting the many tensions between the individual and the context. But it is true, as Sheila says, that this view fails in detaching the individual from the center of social orders or orders shared by individuals. Sheila, do you believe that the concepts of performance and performativity come from these sociologists? And how does the social constructionist understand this?

Sheila McNamee. I think you have articulated well the subtle yet important distinction between the works of Garfinkel and Goffman and the ver- 
sion of social construction that I am talking about here. With deep appreciation for the revolutionary work both proposed, today we can see that the starting place was still the individual. Whether micro or macro in focus, most social theory, until recently, has had a difficult time starting any place but the individual. The significant offering, to me, of social construction is that the starting place for examining the social world is process. By this I mean that we focus on what people are doing and what their "doing" makes. At the micro level that becomes relevant for understanding how particular understandings identities emerge in our unfolding interactions with each other. At the macro level we can now explore how our own actions contribute to the dominance of particular institutional discourses.

As for the concept of performance, I don't think it comes only from the work of these sociologists but it certainly can also be attributed to them. The metaphor of performance is particularly useful for the constructionist. If we think of all action as performed it allows us to imagine alternative performances when the one we are engaged in is not working well. Additionally, the metaphor of performance - most importantly - takes action and meaning out of the head of the individual and places all that we do within the historical, cultural, and local contexts within which we operate. For example, the distinction between "being angry" and "performing anger" is powerful. If you are angry, there's not much that can be done about it. It is what it is and who you are in the moment. Yet the idea of "doing" or "performing" anger acknowledges that (1) we are not free to do just anything we want and be understood as "angry" because we must follow local and cultural conventions for "appropriate" displays of anger and (2) there are alternative performances available. Very powerful ideas.

\section{Dialogue, relation responsibility and social construction future}

RAC. Well, there is a very interesting topic, all which has to do with the generative dialogue, or purposeful dialogues. In Colombia, some people call them "dialogues centered on positive connotation." What would be a purposeful dialogue, and what is not one?

Sheila McNamee. I think we have come to use the term dialogue from a constructionist stance as associated always with generative social transformation. So, I think that we would not connect the idea of dialogue with lack of generativity or opening possibilities. Rather, the idea of dialogue, as one elaboration of social constructionist practice, is that we create a space where people can really pay attention to the ways in which they (together) are creating meaning and understanding. We also create a space where people become curious about differences. It does not mean the dialogue solves a problem or that people come to agreements, but that people are invited into new forms of understanding - particularly they are invited to attempt to understand difference in new ways. This is really what dialogue is about.

So, is every dialogue generative? I think we cannot know until we see what happens after dialogue. Let's say that every dialogue has the possibility of being generative and whether that possibility is realized - is made real - depends upon the participants in the dialogue. I do not think that every dialogue is always generative, but certainly the attempt is to create a dialogue space where new understandings and new meanings emerge.

NVL. Do you think this issue about dialogue is important for all social construction, or only for relational social construction? My question is that not all-social construction is the same, so is dialogue more important for this radically relational orientation?

Sheila McNamee. I think your question raises the opportunity for me to clarify one thing, and that is, I have started to prefer to use the term "relational construction" or "relational constructionism" as opposed to "social construction" or "social construction," because as you pointed out, there are many, many, many understandings of what social construction means and not all are compatible with the ideas that I am trying to talk about today. The relational orientation suggests we look first to relational processes and we can understand who 
we are as people only as a byproduct of relational processes. This is a very different perspective than some other versions of social construction. So I think, yes, I would call this relational constructionist orientation one where dialogue becomes a central resource, a central concept and idea, and in other versions of social construction it probably has no meaning or no place.

NVL: for social construction dialogue is a special form of relationship, a certain kind of social process that involves curiosity, reflection, and coordination. In other words, it is an opportunity to build a unique moment that creates new joint understandings, not necessarily agreement or consensus. Sheila, what can help in creating this generative dialogue? How can you invite a different kind of conversation?

Sheila McNamee. This is precisely what we need to focus on. There is no template, no manual that can inform us. To invite the very different form of conversation that we call dialogue, we need to adopt the relational stance of social construction. Adopting this stance means several things. First, it means that we acknowledge that meaning/knowledge are created in our joint activities. What we do together really matters. It is not about me or you, but about us. If we start from this place, focusing therefore on what we do together rather than on you or me and our specific actions independently, we are already on the way to creating a new conversational space. Second, if we really understand this first move, we will never be too quick to know.

In other words, my own certainty about what you mean, about what is going on, about what we are doing together, about what is right and wrong, etc. is based upon assumptions that might be faulty. If we "pause" instead of acting with certainty that we know what is going on, we position ourselves as curious learners. We become interested in how others make sense of what is going on and curious about the stories and resources they bring to the interaction. Finally (and this is really not finally.... there is much more to be said about all of this - can we have another conversation?), taking care to do whatever seems useful to create the conversational space where different conversations can transpire is useful. This might be as simple as thinking about what context the conversation takes place in - an office or a cozy sitting room. Is there food or beverage available? Do people enter into the conversational space feeling comfortable or do they come suspicious of what will be discussed and what they will be required to do. Preparation is vital. Not a plan (because our tendency to follow a plan no matter what is happening would completely derail any ability to be relationally responsive) but preparation helps to create the conditions for dialogue.

RAC. There is a concept that you have proposed, relational responsibility, which I have found very interesting; how can I have contact with that concept within the exercise of a therapeutic relationship?

Sheila McNamee. First, just briefly, the idea of relational responsibility is a response, was my response to critics to the constructionist approach. Basically, naïve critiques claimed that because constructionists believe that we can construct our world in different ways, there was no responsibility or no moral obligation. If we did not like something, we could simply construct it differently. That is not the case. That is not what social construction is about. I found using the term relational responsibility very useful and I define relational responsibility as being attentive to the process of relating itself. So in a therapeutic context, one would hope that the therapist would be attentive to what is being constructed in conversation with the clients. There are several ways of elaborating relational responsibility. One is to say we are paying attention to what we are doing and shifting the discourse. I think about the multiple voices that we have available for entering into the conversation. For example, when we are talking with someone, we could talk from the voice of pathology or deficit. We could speak with our voice of possibility and potential -- when are people able to be in control of their lives and not let the problem control them. We have multiple voices and if we are being attentive to the process of relating, we are constantly asking ourselves, which voice may I use in this conversation, in this interactive moment, that could be perhaps useful and transformative for us in this therapeutic moment? 
NVL. Yes, Sheila wrote a very interesting article about postmodern ethics in psychotherapy. You said that if you have a postmodern perspective about therapy, it is the necessity to change the focus from individual diagnosis, universal laws and stability that are rooted in tradition empirical knowledge to a practice that takes better account of the uncertainty, continuous change, local and historical contingencies and relationship process. This would imply a different relationship with clients, where the key question is: how can we together expand the resources for action? This leads us to a discourse based more on possibility than on deficit, to a relationship where the authority is not centered solely on the expert and where the main effort is focused on building a relationship that allows transformation. This is relational responsibility in a therapeutic context, as I understand it.

Sheila McNamee. If the therapist is being attentive to the process of relating, then the therapist is continually engaging in some kind of inner dialogue and thinking what voice could I use that could invite this person into a conversation that might be more generative? So, maybe I use the voice of possibility rather than the voice of deficit. Maybe I use the voice of a friend instead of a voice of a therapist, maybe...

NVL. The concept of multiple voices is similar to Bakhtin's concept of polyphony? Have they the same meaning?

Sheila McNamee. Yes, exactly, the notion of multiple voices is absolutely taken from Bakhtin and we say that thought, what we think of as private thinking, always takes place in language, without language there is no thought, and because we participate in so many different language communities, we have multiple voices, multiple resources for action, for talk and action. Bakhtin also introduced us to the idea that nothing is ever said for the first time, that everything is double-voiced. How we will talk to someone tomorrow, give voice to something we have said here? The meaning will be entirely different because we are speaking into a different relationship and in a different context.

NVL: And the same also when he says that we do not have our own voice, in the sense that the voices of all the other people who speak in the past or is speaking in the present are ours...

Sheila McNamee: Yes, everything is borrowed, you know, we live, we are born into traditions and conventions for action. Having two hours for lunch in Colombia is a tradition that you are born into. It seems natural. In other parts of the world, like where I live, you do not even stop for lunch. These are things that we make up ourselves. We carry these traditions, these voices, and these ways of acting. They are borrowed from traditions, contexts and cultures.

RCA: How can we explain the popularity of social construction during a time in which, from what I see, more and more emphasis is given to evidence-based psychology and therapy?

Sheila McNamee: I think evidence-based practice has gained enormous popularity and strength, but there is still a large portion of the population that does believe in evidence-based practice and positivist science. The premise of evidence-based practice is largely drawn from the modernist view of science where it is believed that, if we just find the right method, we will be able to solve problems. However, I think many practitioners - and I mean therapists, consultants, community workers - are very frustrated by evidence-based practice and the limitations this orientation puts on them. At the same time, Scott Miller's "feedback informed therapy" (FIT) is a really good example of trying to find ways of working with clients, that is dialogical, relationally sensitive, open to the construction of new understandings, and at the same time can provide some kind of outcome measures that satisfy people who want evidence-based practices. So I think the struggle with evidence-based practice has really expanded our creativity and innovation by urging us to take these ideas and use them in ways that show other people how generative relational orientations can be.

Can I say something else about evidence-based practice? That is really fascinating to me is that evidence-based practice actually started as a really useful practice. There was this idea that if we could aggregate the data and find out, in general, what is working, then we could give this informa- 
tion to practitioners. Practitioners could then use this information about "what works" in specific cases where they would have to, obviously, adjust the practice to the person(s) with whom they were working.

In this sense, information about the adjustment of the practice within specific cases would be fed back to inform the aggregated data. In this way, evidence based practice requires a constant back and forth between large $n$, aggregated data and application (and adjustment) to specific cases which, in turn, help to adjust and inform the large $\mathrm{n}$ studies. If evidence based practice were actually informed in this way, there would be a constant adjustment in practice. This form of practice initiated within the medical field. Of course, doctors do not deal with aggregated data. They deal with a person. Doctors use the results of aggregated data for different diagnoses and treatments to inform their practice, but the practice should feed back, informing the aggregated data. It is this connection of mutual feedback that has been lost and all we have is oversight boards monitoring treatment to make sure that people only use certain methods because they have been (allegedly) proven through large-scale studies to be more effective. This way of understanding of evidence based practice is senseless. So it becomes a problem despite the fact that the original intent of evidence based practice was quite useful.

NVL. What do you think is the future of social construction? Where will we be in the future?

Sheila McNamee. That is an impossible question to answer. However, through the Taos Institute, we see such incredible innovation around the world. People are putting these ideas into practice in such creative ways. What I find often is that, for some people, living in a relational manner and practicing in a relational way is just a "way of being”. Within the Taos Institute, we have been most interested in taking the ideas of social construction out of the academy. Our effort has been to take this philosophical orientation and recognize the ways in which it informs life. This philosophical orientation is a way of living together in the world. So, at the Taos Institute, we really try to promote and support, in any way we can, people who we see doing relational constructionist work on the ground with people in different contexts.

I think in the future we will see, or we have already seen, a blossoming of practices and large scale social change efforts. We are going to see more and more of this, I believe. And I think the ideas will continue to evolve. In ten years we will be saying some different things, just as we were talking earlier about the move from system theory to social construction. Systems theory was an important innovation against the backdrop of individualism. In 10 or 20 years, there is going to be something that makes what we are talking about right now out-dated, I'm sure.

RAC. For closing... Sheila McNamee, in the next five years, what question will you be tracing?

Sheila McNamee. I think I will continue to pose the question that l already pose daily to myself, which is: how to put these ideas into action for the good of humanity? I think in the next five years I will be thinking about that question and also asking myself specifically, what are the best ways of doing that? Are the best ways of doing that writing, lecturing, talking, or are would it be best to work with people, meet people, and engage in conversations? I think I will also be asking myself how I can help to elevate and support the work that other people are doing around the world; work that is creating better social worlds.

NVL. Well Sheila, we are going to let this conversation end here. Hopefully we will be able to continue this conversation later. Thank you very much for sharing your ideas about social construction and its applications in different areas of psychology, therapy and social change with us. 